University of Nebraska - Lincoln

DigitalCommons@University of Nebraska - Lincoln

1988

\title{
Effects of Oviposition on Remating., Response to Pheromones., and Longevity in the Female Caribbean Fruit Fly., Anastrepha suspensa (Diptera: Tephritidae)
}

J. Sivinski

Insect Attractants, Behavior, and Basic Biology Research Laboratory, USDA-ARS, Gainesville, Florida 32604

R. R. Heath

Insect Attractants, Behavior, and Basic Biology Research Laboratory, USDA-ARS, Gainesville, Florida 32604

Follow this and additional works at: https://digitalcommons.unl.edu/entomologyother

Part of the Entomology Commons

Sivinski, J. and Heath, R. R., "Effects of Oviposition on Remating., Response to Pheromones., and Longevity in the Female Caribbean Fruit Fly., Anastrepha suspensa (Diptera: Tephritidae)" (1988). Entomology Papers from Other Sources. 81.

https://digitalcommons.unl.edu/entomologyother/81

This Article is brought to you for free and open access by the Entomology Collections, Miscellaneous at DigitalCommons@University of Nebraska - Lincoln. It has been accepted for inclusion in Entomology Papers from Other Sources by an authorized administrator of DigitalCommons@University of Nebraska - Lincoln. 


\title{
Effects of Oviposition on Remating, Response to Pheromones, and Longevity in the Female Caribbean Fruit Fly, Anastrepha suspensa (Diptera: Tephritidae)
}

\author{
J. SIVINSKI AND R. R. HEATH
}

Insect Attractants, Behavior, and Basic Biology Research Laboratory, USDA-ARS, Gainesville, Florida 32604

\begin{abstract}
Ann. Entomol. Soc. Am. 81(6): 1021-1024 (1988)
ABSTRACT Female Caribbean fruit flies with oviposition opportunities remate frequently, two-thirds of them after $1 \mathrm{wk}$ and approximately one-third every subsequent week. Those with limited chances to oviposit remate less frequently, and about half of them mate only once during their lifetime. Ovipositing females regain receptivity to male-produced pheromones within a week, unlike nonlaying females. Mortality rates also are higher for egglaying females.
\end{abstract}

KEY WORDS Insecta, conditional strategy, communication, mating behavior

FEMALE MATING FREQUenCy in insects is determined by the requirements of females (e.g., to replenish stored sperm or increase genetic variance in offspring) and the impositions of males (e.g., "trading" access to oviposition site for copulations [Walker 1980]). Among fruit flies there is a range of mating frequencies (Prokopy \& Roitberg 1984). In the Caribbean fruit fly, Anastrepha suspensa (Loew), females visit mating aggregations under their own volition, and male sexual advances toward females on host fruit are seldom successful (Burk 1983). Therefore, remating is under female control and is considered to be infrequent (Prokopy $\&$ Roitberg 1984). However, extensive oviposition opportunities could result in depletion of stored sperm and further copulations. If so, then females might be responsive to male-produced pheromone signals at two or more times in their lives. In addition, the exhaustion of resources and increased metabolic activities associated with greater egg production could influence female senescence and mortality (see Clark and Rockstein 1964, Sokol 1985). All these implications of increased oviposition are examined herein.

\section{Materials and Methods}

Flies were obtained from a colony maintained for over $10 \mathrm{yr}$ at the USDA Insect Attractants, Behavior, and Basic Biology Research Laboratory, Gainesville, Fla. Specimens from this line are in the author's (J.S.) collection, which eventually will be deposited in the Florida State Collection of Arthropods, Florida Department of Plant Industry, Gainesville.

Influence of Oviposition on Remating. To determine if oviposition opportunities and the deple- tion of stored sperm resulted in a greater propensity to remate, females with and without oviposition devices were periodically given an opportunity to copulate. Virgin female flies $(3 \mathrm{~d}$ old) were segregated in separate cages. These cages consisted of two 450-ml transparent plastic cups connected by a cotton wick that led from the water-filled bottom cup through the floor of the upper cup. The top container had a $3.8-\mathrm{cm}$ screened hole for ventilation. A piece of brown sugar-torula yeast taffy on the screen provided food. Oviposition devices consisted of a rolled cloth square ( 6 by $6 \mathrm{~cm}$ ) impregnated with beeswax and placed around the wick. Such waxed cloth is used on a larger scale to obtain eggs from the laboratory colony. In cages without oviposition devices, the cotton wick was pulled as nearly flush to the cage floor as possible to minimize any soft, damp surfaces that might serve as an oviposition site. Flies with access to oviposition devices were presumed to lay more eggs. This was verified by examining the egg production of $15-\mathrm{d}-$ old females kept with two males from $1 \mathrm{~d}$ of age. Ten females with oviposition sites laid an average of $78.3(s=55.9)$ eggs, whereas nine without sites produced a mean of $2.3(s=6)$ (Mann-Whitney test, $P<0.0005$ ). Photoperiod was 12:12 (L:D), and temperatures averaged $26 \pm 1^{\circ} \mathrm{C}$.

As soon as a female reached $10 \mathrm{~d}$ of age, a sexually mature virgin male (10-21 d old) was placed in the cage. This sexual opportunity lasted $1 \mathrm{~h}$ (at 1500-1600 hours EST), after which time the male was removed. The time (after male introduction) mating occurred and the duration of copulations were recorded. Only those females that mated on their first exposure to a male were subsequently given $l \mathrm{~h}$ access to another male on a weekly basis, and these were given up to seven opportunities to 
remate. Forty-six oviposition-device and 40 deviceless females lived at least 1 wk past their first copulation and were included in the data analysis. Statistical analyses were by Wilcoxon paired sample test (Zar 1974), Duncan's (1955) multiple range test as programmed in the Statistical Analysis System package (SAS Institute 1982), and contingency chi-square test (Zar 1974).

Oviposition and Life Span. Because oviposition and continued egg production entail increased metabolism and the expenditure of resources, it was thought they may influence senescence rates and life span. Life spans between females with and without oviposition devices were estimated by noting the last time flies in the previous experiment were seen alive ( $1 \mathrm{wk}$ before the discovery of the corpse). The mortality rates of females in the two treatments were then compared. Statistical analysis was through comparison of regression-line slopes (Zar 1974, SAS Institute 1982).

Oviposition and Receptivity to Male Pheromones. To determine if oviposition opportunities increased mated females' response to sex pheromone, 3-d-old females from the same-age cohort were divided into three categories: virgins, mated and caged with wax and cloth oviposition devices, and mated and caged without oviposition devices. These females were established in sets of 100 in screen cages ( 20 by 20 by $20 \mathrm{~cm}$ ). Rearing conditions were as described previously. Females were assumed to be mated after being kept until age 12 $\mathrm{d}$ with equal numbers of males. Males were then removed, and $7 \mathrm{~d}$ later, when extensive oviposition opportunities had occurred in the cages containing oviposition devices, females of all categories were bioassayed for response to male pheromone. The bioassay was similar to that described by Robacker \& Hart (1984) and Robacker et al. (1985). The ceiling of a cage was divided into four quadrants, on each of which was placed a 5.5-cm filter paper disk. Disks were treated with 100 male-hour equivalents of male Caribbean fruit fly volatiles (where 1 male-hour is recognized by its containing $250 \mathrm{ng}$ of a major constituent, suspensolide (see Chuman et al. in press) in solution in $1 \mathrm{ml}$ of hexane or with comparable amounts of hexane alone. This dosage was chosen simply because, in our experience, it resulted in a considerable and easily observed response. The disks were used immediately after the solvent had evaporated (within $1 \mathrm{~min}$ ). Volatiles from male flies were collected using the volatile collection apparatus described by Landolt \& Heath (1987). The bioassay procedure was as follows. Four hexane-treated disks were placed in the quadrants. After $1 \mathrm{~min}$, the number of flies sitting on the cage calling in each quadrant was counted and the disk in the northeast quadrant replaced with the pheromone-treated disk. After another $5 \mathrm{~min}$, the number of flies in each quadrant was counted again. Because mortality resulted in unequal numbers of flies per cage, the attractancy of the pheromone was calculated as the increase in numbers at the

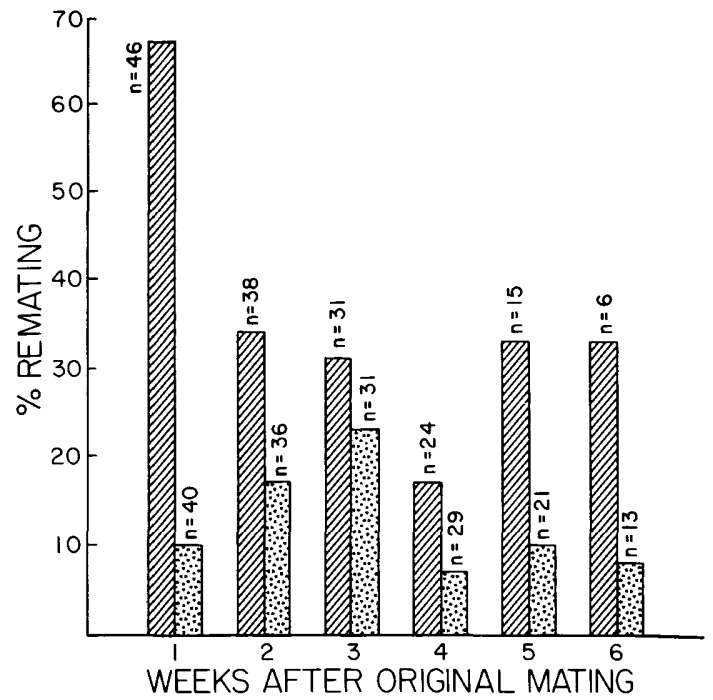

Fig. 1. Percentage of females with oviposition sites (striped bars) and without oviposition sites (stippled bars) remating 1-6 wk after initial copulation; $n$ refers to sample size.

pheromone quadrant divided by the mean change in the control quadrants:

$$
\text { Attractancy }=N_{p}-N_{o p} / \frac{\Sigma N_{c}-N_{o c}}{3}
$$

where $N_{o p}$ is the number originally in pheromone quadrant, $N_{p}$ is the number in pheromone quadrant after exposure to pheromone, $N_{o c}$ is the number in control quadrant, and $N_{c}$ is the number in control quadrant after exposure to pheromone. Female types were tested in rotation with a 15 -min period between tests for the room to be aired. Ten replicates of each female type were performed, five of each on two separate days. Statistical analysis was by Newman-Keuls test (Zar 1974).

\section{Results}

Influence of Oviposition on Remating. Females with oviposition devices are more likely to remate during weekly sexual opportunities than those without (Wilcoxon test, $P=0.025$; Fig. 1). Sixtyseven percent of egg-laying flies remated the week following their initial copulation. This rate falls to an apparent plateau lasting from the third to the sixth mating opportunity, with about one-third of the females remating each time. Multiple sexual experiences thus appear to be the norm for ovipositing female Caribbean fruit flies under these conditions (Fig. 2). Those with no opportunity to oviposit are much more likely to mate only once (contingency chi-square test, $P<0.001$ ). Even so, over half of such females mated two or more times. In addition to mating more often, the rematings of egg-laying females (i.e., with oviposition devices) tend to have longer durations (because of 


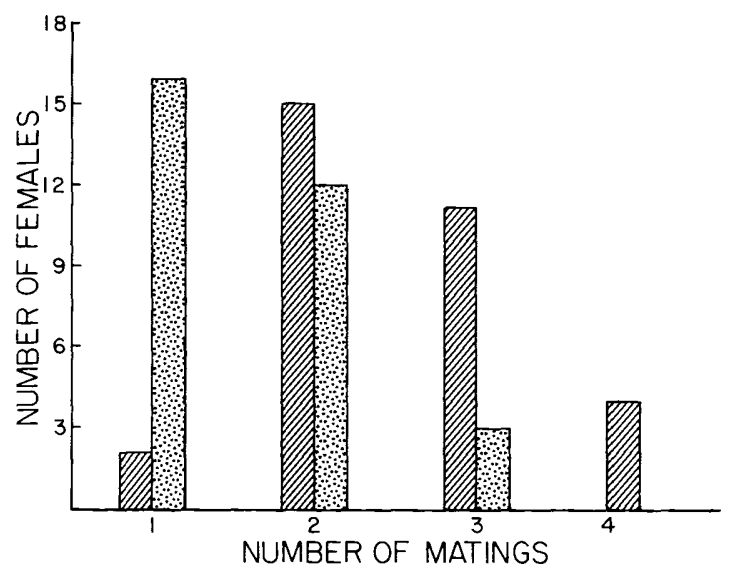

Fig. 2. Number of females with oviposition sites (striped bars) and without oviposition sites (stippled bars) that participated in one through four rematings. To be included, females had to be exposed to four or more remating opportunities.

sample size, only first rematings considered; $N$ ovipositing $=40, N$ nonovipositing $=19$, mean ovipositing $=36.6 \mathrm{~min}, s=15.8$, mean nonovipositing $=26.6, s=12.6, t$ test, $P<0.02$ ). However, there is no difference between the two categories in the time between male introduction and remating (mean ovipositing $=38.2 \mathrm{~min}, s=21.0$, mean nonovipositing $=40.7 \mathrm{~min}, s=15.9, t$ test, $P<0.64$ )

There is no difference in the durations of initial and subsequent copulations within either type of female (Table 1). However, in both categories, first matings are initiated more quickly than at least some rematings (Table 1 ).

Oviposition and Life Span. The presence of an oviposition device influences female mortality (Fig. 3). The death rate is higher for those females that lay eggs (comparison of regression slopes, $P<$ 0.004).

Oviposition and Receptivity to Male Pheromones. Mated females with oviposition opportunities were not only more likely to remate but were also more responsive in later life to male-produced pheromones. (Attractancy in ovipositing females = $3.6, s=3.4$; mean ratio of increase in nonovipositing females $=0.32, s=0.96$; Newman-Keuls test, $P<0.05)$. Ovipositing female response was statis-

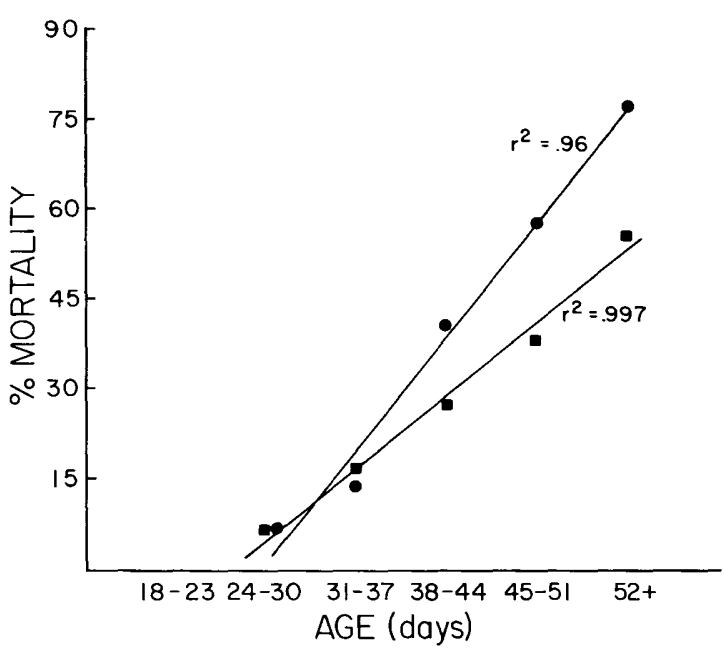

Fig. 3. Percentage of females with (circles) and without (squares) oviposition devices that had died by the ages listed on the $\mathrm{X}$ axis.

tically indistinguishable from that of virgin females (mean virgin female ratio of increase $=3.0, s=$ 3.5, Newman-Keuls test, $P>0.05$ ).

\section{Discussion}

Rematings immediately following an original copulation have been noted in both the Caribbean and Mediterranean fruit fly, Ceratitis capitata (Wiedemann) (Nakagawa et al. 1971, Mazomenos et al. 1977). This has been considered an adaptive response to a sometimes high rate of domestic male insemination failure (Mazomenos et al. 1977). However, such reports of clumped early matings are a different phenomenon from periodic rematings because of possible sperm depletion through extensive oviposition.

In frugivorous Tephritidae, the type of mating system has been thought to influence the propensity of females to remate (Prokopy \& Roitberg 1984). When males defend fruit territories, females may succumb to male sexual advances in order to gain access to oviposition sites. For example, females of Rhagoletis pomonella (Walsh) often encounter males on apples or haws and copulate at weekly

Table 1. Mean durations and times until mating of initial and subsequent matings in female flies with and without oviposition sites

\begin{tabular}{|c|c|c|c|c|}
\hline \multirow{3}{*}{ Mating } & \multicolumn{2}{|c|}{ Mean duration, $\min \pm \mathrm{SE}$} & \multicolumn{2}{|c|}{ Time until mating, $\min \pm \mathrm{SE}$} \\
\hline & \multicolumn{2}{|c|}{ Oviposition device } & \multicolumn{2}{|c|}{ Oviposition device } \\
\hline & Present & Absent & Present & Absent \\
\hline First & $31.3 \pm 2.0 \mathrm{a}(46)$ & $39.4 \pm 2.5 \mathrm{a}(40)$ & $19.3 \pm 2.5 b(46)$ & $27.3 \pm 2.6 \mathrm{~b} \quad(40)$ \\
\hline Second & $36.6 \pm 2.5 \mathrm{a}(40)$ & $26.6 \pm 2.9 \mathrm{a}(19)$ & $38.2 \pm 3.3 \mathrm{a}$ & $40.7 \pm 3.6 \mathrm{ab}(19)$ \\
\hline Third & $30.8 \pm 3.4 \mathrm{a}(18)$ & $34.3 \pm 2.6 \mathrm{a}$ & $32.8 \pm 5.0 \mathrm{ab}(18)$ & $49.0 \pm 4.9 \mathrm{a}$ \\
\hline Fourth & $27.7 \pm 3.4 a \quad(6)$ & & $33.3 \pm 10.1 \mathrm{ab}(6)$ & \\
\hline
\end{tabular}

Means in the same column that share a letter are not different statistically (Duncan's [1955] test). Numbers in parentheses are sample sizes. 
or even shorter intervals. Females of lekking species such as C. capitata are supposed to have greater control over their sexual encounters because they respond to male signals and approach suitors who are not controlling a valuable resource such as fruit or roosting sites. C. capitata females often resist additional mating attempts after a single insemination (Cunningham et al. 1971, Prokopy \& Hendrichs 1979). Copulation also strongly depresses female receptivity in Anastrepha ludens (Loew), the lekking Mexican fruit fly, although it is believed that most long-lived (up to $l \mathrm{yr}$ ) females remate, either being forced by males or regaining receptivity following sperm depletion (Robacker et al. 1985). The Caribbean fruit fly is yet another lekking species and, as such, might be expected to remate infrequently (see Mazamenos et al. 1977). However, our results suggest that remating is more facultative and potentially frequent in female $A$. suspensa, perhaps because sperm storage organs do not have the reserves to meet occasional bonanzas of hosts.

This information is pertinent to two lines of fruit fly studies. First, the operative sex ratio (sexually active males/sexually receptive females) might not be as male-biased as had been assumed in at least this species of lekking fly. This could modify models of sexual selection in the species (for example, see Sivinski \& Burk in press). Previously puzzling phenomena, such as the presence of inseminated females inside lek aggregations, may be explained at least partially by multiple female copulations (see Sivinski in press). Second, female remating might influence control tactics. Trapping with pheromones may be more effective than supposed if mated females, under certain conditions, respond to male-produced pheromones. Our results complement those of Perdomo (1974), who found a considerable response of released mated females to caged males in the field (see Sivinski \& Calkins 1986). Remating by older Caribbean fruit flies and the influence of host availability on reinsemination and rate of mortality could be useful in modeling the response of pest populations to sterile releases and be incorporated into the calculations of overflooding ratios.

\section{Acknowledgment}

Ted Burk, Peter Landolt, Dave Robacker, and Steve Wing made numerous improvements in the manuscript, which was typed by Elaine Turner. Pat Graham provided essential aid in performing experiments.

\section{References Cited}

Burk, T. 1983. Behavioral ecology of mating in the Caribbean fruit fly, Anastrepha suspensa (Loew) (Diptera: Tephritidae). Fla. Entomol. 66: 330-345.

Chuman, T., J. Sivinski, J. Tumlinson, R. Heath \& C. o. Calkins. In press. Variation in the composition of volatiles produced by the male Caribbean fruit fly, Anastrepha suspensa (Loew) (Tephritidae). J. Chem. Ecol.

Clark, A. M. \& M. Rockstein. 1964. Aging in insects, pp. 227-281. In M. Rockstein [ed.], The physiology of insects, vol. 1. Academic, New York.

Cunningham, R. T., G. J. Farias, S. Nakagawa \& D. L. Chambers. 1971. Reproduction in the Mediterranean fruit fly: depletion of stored sperm in females. Ann. Entomol. Soc. Am. 64: 312-313.

Duncan, D. B. 1955. Multiple range and multiple $F$ tests. Biometrics 11: 1-42

Landolt, P. J. \& R. R. Heath. 1987. Role of femaleproduced sex pheromone in behavioral reproductive isolation between Trichoplusia $n i$ (Hübner) and Pseudoplusia includens (Walker) (Lepidoptera: Noctuidae, Plusiinae). J. Chem. Ecol. 13: 1005-1018.

Mazomenos, B., J. L. Nation, w. J. Coleman, K. C. Dennis \& R. Esponda. 1977. Reproduction in Caribbean fruit flies: comparisons between a laboratory strain and a wild strain. Fla. Entomol. 60: 139-144.

Nakagawa, S., G. J. Farias, D. Suda, R. T. Cunningham \& D. L. Chambers. 1971. Reproduction of the Mediterranean fruit fly: frequency of mating in the laboratory. Ann. Entomol. Soc. Am. 64: 949-950.

Perdomo, A. J. 1974. Sex and aggregation pheromone bioassays and mating observations of the Caribbean fruit fly Anastrepha suspensa (Loew) under field conditions. Ph.D. dissertation, University of Florida, Gainesville.

Prokopy, R. J. \& J. Hendrichs. 1979. Mating behavior of Ceratitis capitata on a field caged host tree. Ann. Entomol. Soc. Am. 72: 642-648.

Prokopy, R. J. \& B. D. Roitberg. 1984. Foraging behavior of true fruit flies. Am. Sci. 72: 41-49.

Robacker, D. C. \& W. G. Hart. 1984. A bioassay for investigation of sex pheromones of fruit flies. Southwest. Entomol. 9: 134-137.

Robacker, D. C., S. J. Ingle \& W. G. Hart. 1985. Mating frequency and response to male-produced pheromone by virgin and mated females of the Mexican fruit fly. Southwest. Entomol. 10: 215-221.

SAS Institute. 1982. SAS user's guide: statistics. SAS Institute, Cary, N.C.

Sivinski, J. In press. Lekking and the small scale distribution of the sexes in the Caribbean fruit fly, Anastrepha suspensa (Loew). J. Insect Behav.

Sivinski, J. \& T. Burk. In press. Reproductive and mating behavior. In A. S. Robinson \& G. Hooper [eds.], Fruit flies-biology, natural enemies and control. Elsevier, Amsterdam.

Sivinski, J. \& C. O. Calkins. 1986. Pheromones and parapheromones in the control of tephritids. Fla. Entomol. 69: 157-168.

Sokol, R. S. 1985. Aging in insects, pp. 595-631. In G. A. Kerkut \& L. I. Gilbert [eds.], Comprehensive insect physiology, biochemistry and pharmacology, vol. 10. Pergamon, Oxford, England.

Walker, W. F. 1980. Sperm utilization strategies in nonsocial insects. Am. Nat. 115: 780-799.

Zar, J. H. 1974. Biostatistical analysis. Prentice-Hall, Englewood Cliffs, New Jersey.

Received for publication 19 October 1987; accepted 7 July 1988. 


\section{AVAILABLE FALL 1988}

Nymphs of North American Stonefly Genera (Plecoptera)

Thomas Say Foundation Series, volume 12

by Kenneth W. Stewart and Bill P. Stark

illustrated by Jean Stanger

The definitive sequel to P. W. Claassen's 1931 book Plecoptera Nymphs of America (North of Mexico), this volume is the result of a decade of comparative study by the authors.

Contents:

Introductory chapters on classification, phylogeny, biogeography, ecology of nymphs, and behavior of Plecoptera.

Review of all major systematic and ecological literature on nymphs through 1987.

244 illustrations including 99 full page nymphal habitus and 99 sets of characters for the type or other representative species of all current genera.

New family and generic keys; diagnoses of nymphs of known congener species.

Referencing of all previous nymph descriptions and illustrations.

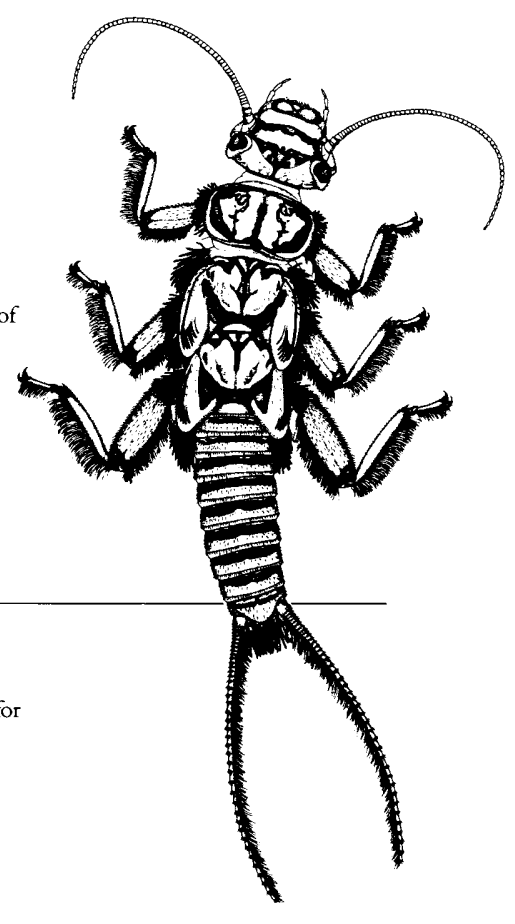

Foreign orders add $\$ 5.00$ for shipping and handling.

Name

Address

City State ZIP

Mail orders to ESA, Box 177, Hyattsville, MD 20781-0177 